\title{
A FAMILY WITH SEVERAL CASES OF HYPOGAMMAGLOBULINAEMIA
}

\author{
BY
}

\author{
W. M. JAMIESON and MARY R. KERR \\ From King's Cross Hospital, Dundee
}

(RECEIVED FOR PUBLICATION NOVEMBER 17, 1961)

Agammaglobulinaemia was first described by Bruton in 1952. Since then it has been shown that $\gamma$-globulin is rarely completely absent and that, therefore, the term hypogammaglobulinaemia is more appropriate; a recent leading article in the Lancet (1961) gives a classification based on Firkin and Blackburn (1958) and Gitlin, Gross and Janeway (1959a): the congenital type has occurred chiefly in males and a sex-linked mode of inheritance has been suggested but, as symptoms do not arise until a few months after birth, 'classical type' is perhaps more appropriate: the primary acquired type becomes manifest at any age, females as well as males being affected; there is little genetical component in its aetiology, though Brem and Morton (1955) describe two adult affected brothers, and Wollheim (1961) describes two adult female cases who were distantly related to each other: the secondary acquired type may occur in association with many diseases, notably multiple myeloma, lymphoma and chronic lymphatic leukaemia.

The findings in 61 patients with hypogammaglobulinaemia (excluding the secondary acquired type), brought to the notice of the Medical Research Council Working Party on this condition, reveal that among children males predominate by nearly $5: 1$, whereas among adults females predominate by about 3:2 (Squire, 1960). In 29 male children studied, there were three pairs of brothers, but no consanguinity was demonstrated among 22 females in the series.

Classification of the idiopathic cases of infancy is difficult. The few female infants are almost exclusively of the primary acquired type, a group in which one might expect an equal number of infant males, but these males have not yet been distinguished clinically from those of the classical type, and it is well known that sex-linked recessive conditions, such as haemophilia, do not always announce themselves by a positive family history.

The family history in the cases under study clearly indicates the classical type, there being three definite cases and one probable case in the youngest generation, and the possibility of six further cases in the two previous generations.

The first cases of classical hypogammaglobulinaemia in Britain were reported in Glasgow by Hutchison (1955), and these were later shown to have had pneumonia of pneumocystis carinii type. This association has since been recorded in Scotland by Bird and Thomson (1957) in Dundee.

\section{Family Tree}

The salient features of the family history are as follows (see Figure):

I.1 had two daughters, one of whom, II.2, died at 34 months, in 1893 , the certified cause of death being 'pneumonia and cardiac failure'. The child had apparently been healthy until this sudden fatal illness.

II.1 had three sons and three daughters. All the boys died in infancy, the certified causes of death being in III.2 'gastro-intestinal catarrh' (age 2 weeks), in III.5 'bronchopneumonia' (age 9 months), and in III.6 'miliary tuberculosis, diarrhoea, pulmonary phthisis and convulsions' (age 6 months).

III.1 has one son who has enjoyed good health and whose own family of three sons and two daughters are all well.

III.3 is apparently a carrier. Three of her grandchildren, V.15, 16, 17, are definite cases of hypogammaglobulinaemia, and her own sons all died in early childhood, the certified causes of death being in IV.5 'bronchopneumonia, cardiac failure, postoperative shock' (age 34 months) - the tonsils had been removed two weeks before death, in IV.6 'bronchopneumonia' (age 13 months), and in IV.9 'bronchopneumonia' (age 8 months).

III.7 has two daughters, and two grandchildren (unlike-sexed twins) who are only a few months old and have not yet been investigated.

IV.2 has six daughters and no sons.

IV. 3 is a definite carrier. George, the oldest son, V.12, is now 13 years old, his health is good and his level of $\gamma$-globulin is normal $(1,120 \mathrm{mg}$. per $100 \mathrm{ml}$.). Margaret, V.13, is now aged 9 years, is physically well but has a moderate degree of mental defect; the level of $\gamma$-globulin is $960 \mathrm{mg}$. per $100 \mathrm{ml}$. Robert, V.14, very probably had deficiency of $\gamma$-globulin which may have 


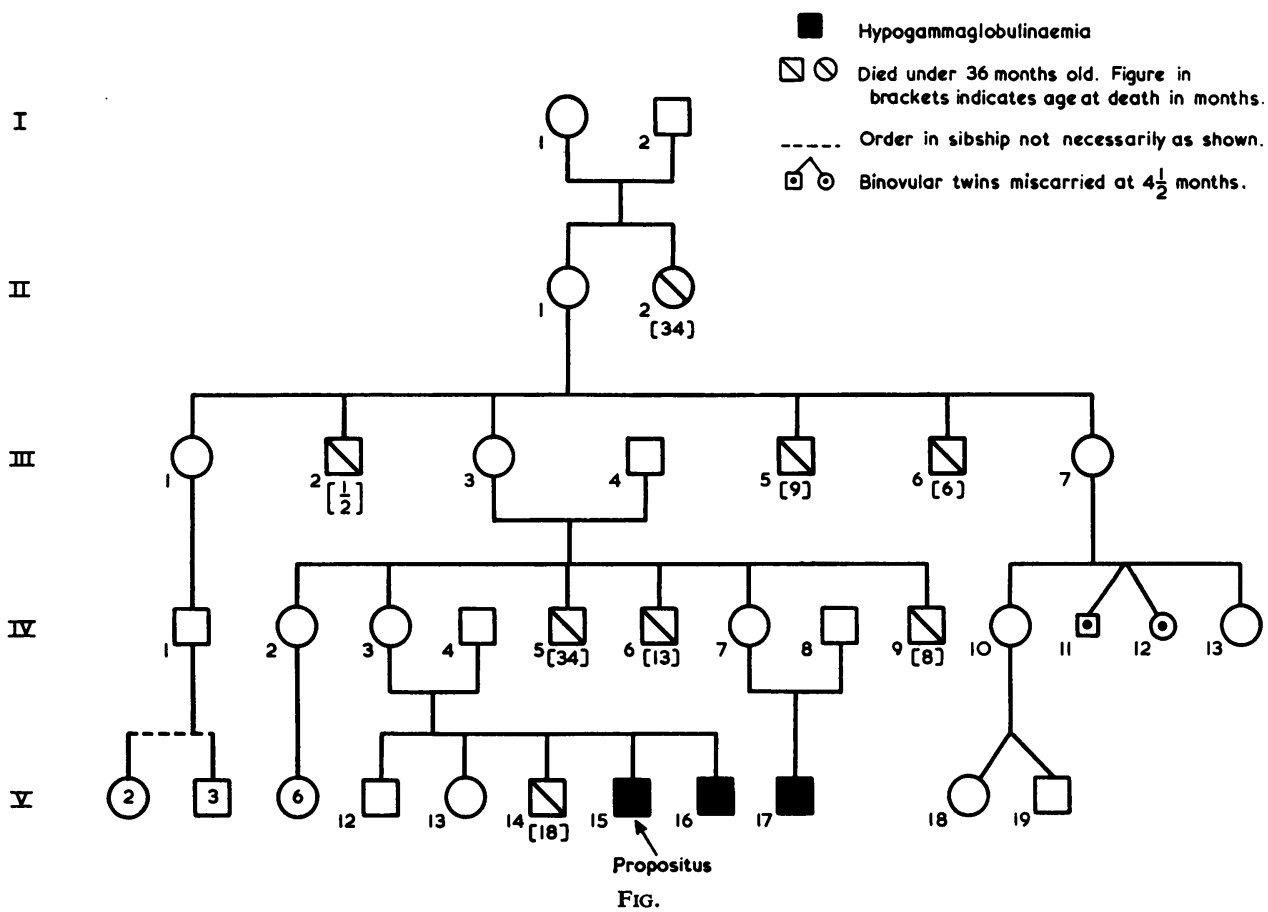

contributed to his death; both Paul and Roy $(\mathrm{V} .15,16)$ are suffering from hypogammaglobulinaemia and have been accepted by the Medical Research Council working party for inclusion in their therapeutic trial; the case histories of all three $(\mathrm{V} .14,15,16)$ will be discussed in detail.

IV.7 has a young son, John, V.17, who is also deficient in $\gamma$-globulin and who was later accepted for inclusion in the M.R.C. therapeutic trial (see below).

Estimation of the level of $\gamma$-globulin in certain other members of the family was carried out with the following results: III.3, 1,120 mg. per $100 \mathrm{ml}$.; III.4, $1,120 \mathrm{mg}$. per $100 \mathrm{ml}$.; III.7, 1,560 mg. per $100 \mathrm{ml}$; IV.2, 1,120 mg. per $100 \mathrm{ml}$; IV.3, $960 \mathrm{mg}$. per $100 \mathrm{ml}$; IV.4, $800 \mathrm{mg}$. per $100 \mathrm{ml}$; IV.7, $1,120 \mathrm{mg}$. per $100 \mathrm{ml}$.

\section{Case Reports}

Case 1, Paul (V.15). This child was born in December 1956, a full-time normal delivery, and thrived until the age of 6 months when he developed pneumonia; this responded to antibiotic therapy. He then had frequent and severe attacks of coryza till the seventeenth month, when he had a low-grade septic arthritis of the left shoulder and was admitted to an orthopaedic unit. The shoulder lesion responded slowly to antibiotic treatment, but at 20 months, and while still in the orthopaedic unit, he developed a febrile illness with signs of meningeal irritation followed by weakness of the right leg. Cerebrospinal fluid contained 60 lymphocytes per c.mm., and a clinical diagnosis of acute anterior poliomyelitis was made. No virus was isolated from stool culture (six weeks after the onset), and serological investigation (six months after the onset) showed no significant titre of antibody to poliovirus (vide infra).

He next contracted chickenpox which was uncomplicated, and thereafter had several pyrexial episodes for which no cause was found. In October 1958 he developed acute otitis media and was transferred to King's Cross Hospital for further investigation. Shortly after transfer he had lobar pneumonia which responded slowly to antibiotic therapy, and in convalescence he was found to have a large unhealthy ulcer of the buccal mucosa. His general appearance was that of a listless, toxic, underweight child, taking no interest in his surroundings. There was a lower motor neurone type of paralysis affecting muscles of the right leg, especially quadriceps femoris, tibialis anterior and calf muscles. There was neither hepatomegaly nor splenomegaly and there appeared to be no lymphadenopathy. During each episode of febrile illness the stools became bulky and loose, but no intestinal pathogen was ever isolated.

\section{Investigation}

HaEmatology. The most striking feature here was neutropenia. Total leucocyte counts ranged from 4,000 to 9,500 per c.mm., the polymorphs ranging from 300 to 1,800 per c.mm. The lowest counts were usually obtained at the onset of febrile incidents, and initially we suspected cyclical agranulocytosis. Examination of bone marrow confirmed a deficiency of cells of the myeloid series but showed no abnormal cells. Plasma cells were $0 \cdot 2 \%$. The leuco-erythroblastic ratio was 0.3. Other findings (Hb, R.B.C., P.C.V., M.C.V., M.C.H.C.) were all within the normal range. Serial 
counts following therapy with $\gamma$-globulin showed little change from the initial findings and there is still neutropenia after two years on treatment.

Plasma Proteins. In October 1958, serum protein was found to be $6 \cdot 2 \mathrm{~g} . / 100 \mathrm{ml}$. (albumin $5 \cdot 2$, globulin 1.0). Electrophoresis showed normal bands for albumin and $\beta$-globulin with an increase in $\alpha_{1}$ and $\alpha_{2}$ fractions. The $\gamma$-globulin band was decreased but not entirely absent. Estimation of $\gamma$-globulin was approximately $200 \mathrm{mg} . / 100 \mathrm{ml}$. (method of Wolfson, Cohn, Calvary and Ichiba, 1948). Later (December 1958), in two samples examined by Dr. J. F. Soothill, the levels were shown to be 80 and $60 \mathrm{mg} . / 100 \mathrm{ml}$. (method described by Gell, 1957, and by Kekwick, Vallet, Cutbush, Mollison, Thomas, Gell and Soothill. 1961). $\gamma$-macroglobulin was $150 \%$ of that in a normal serum. A diagnosis of the classical type of hypogammaglobulinaemia was made.

ANTIBODY Formation. In view of the low $\gamma$-globulin levels, estimations were made of the antibody content.

(a) Anti $\mathbf{A}$ and anti $\mathbf{B}$ iso-agglutinins were present only in a titre of 4 (blood group $O$ ).

(b) Antibody to poliovirus was of obvious interest in view of the clinical history. Titres to the three types of poliovirus are given in Table 1.

These levels were no greater than might have been expected from the weekly injections of $\gamma$-globulin given therapeutically. The child was inoculated with poliovaccine in June/July 1959, and two months later antibody levels were $T_{1}-8, T_{2}-16, T_{3}-16$. It is of interest that there was evidence of infection with poliovirus types 2 and 3 in the family (Table 2).

(c) Anti-staphylolysin titre $\mathbf{0} \cdot 23$.

(d) Herpes simplex titre 2 .

(e) The child had not been inoculated with diphtheria toxoid and had not been vaccinated against smallpox.

Tuberculin Test. The Mantoux test was positive six weeks after B.C.G. vaccination performed at the age of 15 months. A further test (February 1961, age 4) was positive in a dilution of 1:1,000 (oedema and erythema $25 \times 25 \mathrm{~mm}$.).

Chest Radiograph. Radiological examination at the age of 6 months (following pneumonia) showed normal lung fields. A further film, at the age of 17 months, showed discrete nodular lesions throughout both lung fields, some with minimal calcification, but there was no enlargement or calcification of hilar nodes. Since then, serial films have shown progressive calcification of the lesions, and the latest film, at just over 4 years of age, shows this to be almost complete, the calcification being of an unusual ring type. There is still no evidence of calcification in hilar lymph nodes.

The interpretation of the findings is not easy. Possibilities appear to include tuberculosis, occurring either naturally or following B.C.G. vaccination, mycotic or protozoal disease, and pneumocystis lung. Somewhat similar findings in congenital agammaglobulinaemia have been described by Margulis, Feinberg, Lester and Good (1957); they stress as a point of diagnostic importance
TABLE 1

\begin{tabular}{|c|c|c|c|c|}
\hline Date & & $\mathrm{T}_{1}$ & $T_{2}$ & $T_{3}$ \\
\hline $\begin{array}{l}\text { March 5, } 1959 . \\
\text { April } 21,1959 . \\
\text { May } 5,1959\end{array}$ & $\begin{array}{c}\ldots \\
\cdots \\
\ldots\end{array}$ & $\begin{array}{r}8 \\
<4 \\
8\end{array}$ & $\begin{array}{r}8 \\
<4 \\
8\end{array}$ & $\begin{array}{r}8 \\
<4 \\
8\end{array}$ \\
\hline
\end{tabular}

'extensive pulmonary parenchymal disease with paradoxical absence of hilar node enlargement', but they make no mention of calcification. Our films have been studied by several experienced radiologists and chest physicians, and they feel that the diagnosis rests between tuberculosis and histoplasmosis. A positive Mantoux test was got after the B.C.G. vaccination and this is still strongly positive (vide supra). We have also done a histoplasmin skin sensitivity test; this gave a result of doubtful significance (erythema and oedema $5 \times 5 \mathrm{~mm}$.). The parents have also been skin tested with histoplasmin and the results are negative. The father was in Tripoli for five years, the mother for 15 months and Paul (V.15) was not born until a year after their return to the United Kingdom and has not been out of this country since birth. Antibody tests have also been carried out in Paul for toxoplasma. The dye test was positive only in a titre of 8 , and complement-fixation test was negative.

Progress. In December 1958, the child was accepted for inclusion in the M.R.C. therapeutic trial and weekly injections of $\gamma$-globulin were begun, with an almost immediate improvement. The general condition became better, the child was brighter and more alert mentally, a chronic ulcer of the mouth healed rapidly, and there was steady gain in weight. During the first six months of therapy the only infection was mild coryza on two occasions and this despite the fact that he was in a busy ward receiving numerous patients with respiratory infection. Since his discharge from hospital in May 1959 he has had infrequent attacks of mild coryzal illness and mild catarrhal otitis media. He was readmitted once with acute bronchitis which cleared rapidly on antibiotic therapy. At age just over 4 years his height is 41 in. $(114 \cdot 1 \mathrm{~cm}$.) and his weight $38 \cdot 5 \mathrm{lb}$. $(17 \cdot 45 \mathrm{~kg}$.) (normals $40 \cdot 16 \pm 1 \cdot 74$ and $36 \cdot 75 \pm 4 \cdot 99$ respectively-Acheson, Kemp and Parfit, 1955). At present he is a sturdy, healthy and happy lad who, despite the limitation of a leg calliper, enjoys the life of a normal boy of his age.

Case 2. Roy (V.16). At the time of Paul's admission to King's Cross Hospital (October 1958), his younger brother Roy (born April 4, 1958) was aged 6 months. His had been a normal delivery at full term and he

TABLE 2

\begin{tabular}{l|r|r|r|r}
\hline & & $\mathrm{T}_{1}$ & $\mathrm{~T}_{2}$ & $\mathrm{~T}_{3}$ \\
\hline Father $-\mathrm{IV} .4$ &. & 40 & $<40$ & $<40$ \\
Mother $-\mathrm{IV} .3$ & $\cdots$ & 8 & 64 & 128 \\
George $-\mathrm{V} .12$ & $\cdots$ & 16 & 64 & 128 \\
Margaret $-\mathrm{V} .13$ &. & 8 & 128 & 128 \\
\hline
\end{tabular}


appeared then a normal healthy infant with no history of illness. Roy was well until the age of 8 months when he had a series of coryzal attacks, some of which were accompanied by mouth ulceration. He developed acute bronchitis at $\mathbf{1 0}$ months, and by the eleventh month his general condition was deteriorating, with septic spots on hands and face and crops of styes on eyelids.

His $\gamma$-globulin was first estimated at the age of 11 months (March 1959) and was $280 \mathrm{mg}$./100 ml. ( $\gamma$-macroglobulin was $150 \%$ of that in a normal serum); tests were repeated at monthly intervals, and the level fell to $200 \mathrm{mg}$. and then to $140 \mathrm{mg} . / 100 \mathrm{ml}$. (method described by Gell, 1957). On this last result he was admitted to the M.R.C. therapeutic trial, and weekly injections of $\gamma$ globulin were begun. He was then 14 months.

Even after the start of therapy with $\gamma$-globulin his progress has been quite eventful. An inguinal abscess (July 1959) was followed by a large deep ulcer of tonsil and palate (August 1959), the latter responding only very slowly to treatment with antibiotics and the local application of cortisone. From November 1959 until February 1960 his condition improved, but he then developed jaundice. Clinical findings and liver function tests were consistent with viral hepatitis, and he made a rapid and complete recovery. Thereafter he remained free from infection until April 1960 when he had acute tonsillitis, otitis media and recurrence of skin sepsis. Pyodermia continued until July 1960, when he had acute bronchitis. From then until December 1960 he had a succession of respiratory infections, chiefly coryzal in nature but including one episode of lobar pneumonia. A point of special interest was that, as in the case of his brother, each febrile upset was almost invariably associated with the passage of loose, bulky stools. Since December 1960 (at the age of 2 years 8 months) his general condition has improved, and he now looks in a more healthy state than at any time since his infectious troubles began. At 3 years of age his height is 38.5 in. $(97.8 \mathrm{~cm}$.) and his weight $37.5 \mathrm{lb}$. (17 kg.) (normals $37 \cdot 28 \pm 1 \cdot 60$ and $32 \cdot 21 \pm 4 \cdot 12$-Acheson et al., 1955).

\section{Investigation}

HAEMATOLOGY. The blood picture was similar to that of his brother Paul. Serial total and differential leucocyte counts showed either normal or slightly reduced total counts which did not increase significantly with infectious episodes. There was definite neutropenia and increase in the monocyte series. A typical count (January 1960) is shown in Table 3.

Examination of bone marrow has not been carried out.

\section{ANTIBODy Formation}

(a) Iso-agglutinins to $A_{1}$ and to $B$ cells were not detectable (his blood group is $A_{2}$ ).

(b) Poliovirus antibody titres are given in Table 4.

(c) Anti-staphylolysin titre $<0.02$ (May 1959).

(d) Anti-streptolysin titre $<10$ (April and May 1959).

(e) Smallpox vaccine and diphtheria prophylactic had not been given.

Tuberculin Test. The Heaf test was negative (February 1961).
TABLE 3

\begin{tabular}{llccc|r}
\hline Total white cells (per c.mm.) & $\ldots$ & $\ldots$ & $\mathbf{8 , 2 5 0}$ \\
Neutrophils & $\ldots$ & $\ldots$ & $\ldots$ & $\ldots$ & 830 \\
Eosinophils & $\ldots$ & $\ldots$ & $\ldots$ & $\ldots$ & 80 \\
Lymphocytes & $\ldots$ & $\ldots$ & $\ldots$ & $\ldots$ & 5,690 \\
Monocytes & $\ldots$ & $\ldots$ & $\ldots$ & $\ldots$ & 1,650 \\
\hline
\end{tabular}

Chest Radiograph. This has given consistently normal findings, apart from radiological confirmation of lobar pneumonia on a single occasion.

Case 3. Robert (V.14). This older brother was born seven weeks prematurely on September 14,1953 . He remained well until the age of 6 months when he began to have attacks of diarrhoea and failed to thrive. At 7 months he was admitted to a hospital in Aberdeen where investigation failed to reveal an infective cause of the diarrhoea and a diagnosis of 'fatty diarrhoea' was made. When the child was aged 11 months the family moved to Tripoli (August 1954). During the voyage, and after arrival, Robert continued to have bouts of diarrhoea. In October 1954, he was admitted to the Military Hospital, Tripoli, for investigation, and the rest of the history is extracted from case records kindly lent by that hospital. The possibility of idiopathic steatorrhoea was considered, but fat balance studies could not be carried out and, without a firm diagnosis, the child was discharged in December 1954. He was readmitted in February 1955 because of unsatisfactory progress and because radiological examination showed an abnormality in the right lung field: 'There is almost homogeneous shadowing of right upper zone with a welldefined outer border. The appearances suggest thymic shadow rather than pneumonia.' Further examination two weeks later was reported as being 'more suggestive of glandular enlargement than of thymic shadow'. At this time five gastric washings and three stools were examined for $\boldsymbol{M}$. tuberculosis but all cultures were negative. Mantoux reaction was negative, but when repeated in March 1955 was positive $(12 \mathrm{~mm}$.) in a dilution of $1: 1,000$, and a further radiographic report stated 'there is now shadowing above right hilum and in right cardiophrenic region and possibly in left parahilar region. The appearances suggest primary tuberculosis with glandular enlargement and probably some pulmonary infiltration ...' (unfortunately it has not been possible to find these films).

TABLE 4

\begin{tabular}{|c|c|c|c|c|c|}
\hline Date & & $\mathbf{T}_{1}$ & $\mathrm{~T}_{2}$ & $\mathbf{T}_{3}$ & Remarks \\
\hline April 21, 1959 & . & $<4$ & $<4$ & $<4)$ & Pretherapeutic $\gamma$ - \\
\hline $\begin{array}{l}\text { May } 17,1959 \ldots \\
\text { June } 30,1959 \ldots\end{array}$ & $\begin{array}{l}. \\
.\end{array}$ & $\begin{array}{r}<4 \\
16\end{array}$ & $\begin{array}{r}<4 \\
8\end{array}$ & $\begin{array}{c}<4 \\
64\end{array}$ & $\begin{array}{l}\text { globulin } \\
\text { Post-therapeutic } \gamma \text { - } \\
\text { globulin }\end{array}$ \\
\hline August 23, 1959 & . & 8 & 32 & 32 & $\begin{array}{l}\text { Three weeks after } \\
\text { polio inoculation } \\
\text { (2) }\end{array}$ \\
\hline September 22, 1959 & . & 16 & 32 & 64 & $\begin{array}{l}\text { Seven weeks after } \\
\text { polio inoculation } \\
\text { (2) }\end{array}$ \\
\hline
\end{tabular}


TABLE 5

\begin{tabular}{|c|c|c|c|}
\hline & $\underset{1955}{\text { February }} 19$ & $\underset{1955}{\operatorname{March} 7,}$ & $\underset{1955}{\operatorname{March} 18,}$ \\
\hline $\begin{array}{cc}\text { Total cells (per c.mm.) } \\
\text { Neutrophils } & \text {. } \\
\text { Eosinophils } & \text {. } \\
\text { Lymphocytes } & \text {. } \\
\text { Monocytes } & \text {. } \\
\text { Normoblasts } & \text {. }\end{array}$ & $\begin{array}{r}8,600 \\
860 \\
1,120 \\
6,020 \\
340 \\
260\end{array}$ & $\begin{array}{r}5,300 \\
580 \\
270 \\
4,240 \\
210 \\
-\end{array}$ & $\begin{array}{r}5,000 \\
2,700 \\
100 \\
2,050 \\
150 \\
-\end{array}$ \\
\hline
\end{tabular}

The child was treated with streptomycin and paraamino-salicylic acid, but his condition progressively deteriorated; pyrexia, $103^{\circ}$ F. $\left(39 \cdot 4^{\circ}\right.$ C.), continued, and signs of bronchopneumonia supervened; on March 28,1955 , he collapsed suddenly and died. He was then 18 months of age.

Leucocyte counts had been done on several occasions and are of interest since, although variable, they were either normal or low, and two show severe neutropenia (Table 5).

\section{Extract from Autopsy Report}

-... Both trachea and bronchi contain a moderate amount of blood-stained froth but appear otherwise normal. The right upper lobe is adherent at its upper limit to pleura. The right upper lobe is extensively infiltrated with fibro-caseous white patches completely confluent in its upper half. There are some small cavities containing whitish-yellow pus and some enlarged hilar glands. There is no fluid in the pleural cavities. No miliary nodules can be seen on the pleural surfaces. There is some involvement of the left upper lobe in the hilar area ... There are no visible signs of tubercles on the peritoneum. The spleen shows a few small white dots on its surface. The liver is not enlarged. Its cut surface is pale and shows small white areas like tubercles.

Histology: (1) Section of affected lung tissue shows fibro-caseous tuberculosis.

(2) Section of liver tissue shows the formation of small early tubercles.

Opinion: Death was due to acute miliary tuberculosis resulting from a respiratory focus.'

Comment. Whether or not this child had a deficiency of $\gamma$-globulin, it is worth noting the recurrent bouts of diarrhoea with failure to thrive from the age of 6 months, the family similarity of the blood picture with its neutropenia, and the mother's statement that the appearance of Roy in his worse periods closely resembled what she had seen in the baby that died. The autopsy findings do not fit the description of the lungs of children with pneumocystis carinii infection (Bird and Thomson, 1957), but in view of the findings described above it is rather surprising that five gastric washings were negative for M. tuberculosis.

Case 4. John (V.17). This child, a cousin of the propositus, was born in U.S.A. (October 24, 1959) and was delivered normally at full term. At the age of $4 \frac{1}{2}$ months he was brought by his mother to this country. He had been healthy since birth, but in view of the family history, investigation of the level of $\gamma$-globulin was undertaken, and the initial result was $140 \mathrm{mg} . / 100 \mathrm{ml}$. The level at 6 months was $70 \mathrm{mg}$. and at $6 \frac{1}{2}$ months was $60 \mathrm{mg} . / 100 \mathrm{ml}$. (method described by Gell, 1957). At this point he was admitted to the Medical Research Council's therapeutic study, and treatment with $\gamma$ globulin was begun in June 1960 at the age of 8 months. Immediately before this, he had developed coryza with cough which persisted for about one month. A month later he again had coryza which again was slow to clear. Radiograph of the chest showed normal lung fields.

A leucocyte count was 9,600 per c.mm. (polymorphs $40 \%$, lymphocytes $58 \%$, monocytes $2 \%$ ). In September 1960 the child's mother decided to return to U.S.A., and arrangements were made for continuation of therapy there. Since then his progress has apparently been satisfactory, although recently he developed a mouth ulcer.

\section{Discussion}

The newborn child begins life with a supply of $\gamma$-globulin of varied amount, but this is low by the end of the first month and only begins to rise after the third month (Orlandini, Sass-Kortsak and Ebbs, 1955). Failure to produce $\gamma$-globulin in the normal way - classical hypogammaglobulinaemia-is generally manifest by recurrent serious infection mainly of bacterial type.

In our cases, however, clinical manifestations did not appear until between the sixth and eighth months of life. Paul and Roy $(\mathrm{V} .15,16)$ had certain striking features in common-frequent infection of upper respiratory tract, ulceration of mouth, and diarrhoea with the passage of soft, bulky stools. The general appearance of the children when most ill was very similar; they were pale, hypotonic, lethargic and quite disinterested in their surroundings with irritability and frequent temper tantrums. Skin sepsis was a feature of one case, but absent in the other. Upper respiratory tract infection was frequent in both and an attack of lobar pneumonia in Paul (V.15) very nearly proved fatal despite intensive antibiotic therapy.

Children with hypogammaglobulinaemia are said to respond normally to virus infection although vaccinia gangrenosa, almost always fatal, has been reported not infrequently (Somers, 1957). While one of our patients developed poliomyelitis with paralysis of a lower limb and also had chickenpox, and another had virus hepatitis, these virus infections pursued a fairly normal course. Admittedly, the attack of paralytic poliomyelitis was followed by extremely poor antibody response and subsequent inoculation with polio vaccine failed to provoke any significant antibody response. This compares interestingly with Pearce and Perinpanayagam's report (1957) of paralytic poliomyelitis (poliovirus 
type 1) in a female child with hypogammaglobulinaemia while receiving $\gamma$-globulin; there was no significant subsequent rise in circulating antibody. Although the content of circulating antibody is not a sufficient index of immunity in viral disease (Burnet, 1959), the general deficiency of antibody in our cases is reaffirmed by the low titres of isohaemagglutinins, anti-streptolysin and anti-staphylolysin.

The association of hypogammaglobulinaemia with granulocytopenia, already recorded by Janeway (1954), Elphinstone, Wickes and Anderson (1956) and others was a feature of our cases and is our main reason for believing that V.14 must have had hypogammaglobulinaemia. The bacterial infections we studied produced no appreciable increase of granulocytes, and it may well be that the leucopenia is a pleiotropic effect of the hypogammaglobulinaemia allele. This combined deficiency in the defence against bacterial infection demands not only a supply of extraneous $\gamma$-globulin but also a skilful administration of antibiotics.

The association of deficiency of $\gamma$-globulin with pneumonia due to pneumocystis carinii has been recorded in this country, but the reports are few, and the factual information is mainly morbid anatomy. There was long-term involvement of the respiratory system in two of our cases $(\mathrm{V} .15,14)$, but in neither was the diagnosis either obvious or certain, and we feel reluctant to ascribe the changes to any of the usual diseases even if we cannot justifiably implicate the very unusual pneumocystis disease.

Substitution therapy with gammaglobulin seems to be doing well in V.15 and 16, and the stage between the ages of 6 and 30 months, which we suspect is a dangerous period, has been successfully negotiated. A more detailed and a wider study of the therapy of these and other cases will be contained in the report of the M.R.C. working party.

Genetics. The type of hypogammaglobulinaemia affecting infant boys has been described as a sexlinked recessive condition by Gitlin, Janeway, Apt and Craig (1959b) and by others, and the present pedigree is best interpreted in this way, although there is, for all such families, the theoretical alternative that, by analogy with early baldness, the condition may be due to heterozygous expression of an autosomal gene with no observable effect in the female. Since the affected males have thus far rarely if ever survived to have children, it has not been possible to apply the crucial test for an $\mathrm{X}$-borne allele, namely to show that all male children of affected males were unaffected, since $Y$ and not $\mathrm{X}$ is inherited from the father. The alternative test, that of showing the hypogammaglobulinaemia locus genetically linked to such a known sex-linked locus as that for protanopia, is impracticable in this family, since most of the few surviving males are too young to be scored for colour-blindness; we do know, however, that George, V.12, is not colour-blind. Primaquine sensitivity, which would be as good an indicator as colour-blindness, is extremely rare in Scotland.

Whichever of these two genetical mechanisms is actually operative, the expected proportion of affected males among the male offspring of carrier females would be $0 \cdot 5$. The observed proportion in this pedigree is rather higher, but even if we were to attribute all the early male deaths (except III.2) to hypogammaglobulinaemia, the excess would not be statistically significant. There are then seven 'affected' out of a possible nine, if we discount two affected individuals as a rough ascertainment correction (two cases make the 'positive family history' usually required to prompt such a genetical test). It is not known whether III.1 is a carrier, so the genetical expectations for these nine are 4.25 affected, 4.75 unaffected (unadjusted $\chi^{2}=3.4$ for 1d.f.: $0 \cdot 1>p>0 \cdot 05$ ). This $\chi^{2}$ could be reduced by Yates' correction for small expectations by a more generous ascertainment correction, and by more rigid criteria for classification as 'affected'. There are thus no grounds for doubting Mendelian ratios in this family.

\section{Summary}

The classical type of hypogammaglobulinaemia is described in a Dundee family. The clinical features are described in three proved and one probable case, and attention is drawn to the possibility of six further cases. The pattern of inheritance is most probably that of a sex-linked recessive condition, as suggested by others.

We wish to thank the Medical Research Council Working Party for their interest and for supplies of $\gamma$-globulin. We are particularly indebted to Dr. J. Renwick, Senior Lecturer in the Department of Human Genetics, University of Glasgow, for his invaluable assistance with the genetical aspects. Estimations of levels of $\gamma$-globulin were carried out in the Department of Experimental Pathology, University of Birmingham, by Dr. J. F. Soothill, and serological investigation of antibody was done at the Central Public Health Laboratory by Dr. F. O. MacCallum. On various points we have sought expert opinion and gratefully acknowledge help received from Drs. G. Simon, E. Samuel, C. Pickard, Professors J. W. Crofton and A. C. Lendrum, Drs. R. N. Johnston, C. Cameron, and from Mr. J. E. Cant, City Registrar, Dundee. Some of the initial investigation of V.15 was carried out in the Department of Orthopaedics, 
Bridge of Earn Hospital. It is a great pleasure to acknowledge the willing co-operation of all members of this particular Dundee family.

\section{REFERENCES}

Acheson, R. M., Kemp, F. H. and Parfit, J. (1955). Height, weight, and skeletal maturity in the first five years of life. Lancel, 1, 691 .

Bird, T. and Thomson, J. (1957). 'Pneumocystis carinii' pneumonia. ibid., 1, 59.

Brem, T. H. and Morton, M. E. (1955). Defective serum gamma globulin formation. Ann. intern. Med., 43, 465.

Bruton, O. C. (1952). Agammaglobulinemia. Pediatrics, 9, 722.

Burnet, M. (1959). The Clonal Selection Theory of Acquired Immunity. Cambridge University Press.

Elphinstone, R. H., Wickes, I. G. and Anderson, A. B. (1956). Familial agammaglobulinaemia. Brit. med. J., 2, 336.

Firkin, B. G. and Blackburn, C. R. B. (1958). Congenital and acquired agammaglobulinaemia; a report of four cases. Quart. J. Med., 27, 187.

Gell, P. G. H. (1957). The estimation of the individual human serum proteins by an immunological method. J. clin. Path., serum 67

Gitlin, D., Gross, P. A. and Janeway, C. A. (1959a). The gamma globulins and their clinical significance. II. Hypogammaglobulinemia. New Engl. J. Med., 260, 72.
-—, Janeway, C. A., Apt, L. and Craig, J. M. (1959b). Agammaglobulinaemia. In Cellular and Humoral Aspects of Hypersensitivity States, ed. H. S. Lawrence. Hoeber, New York. Hutchison, J. H. (1955). Congenital agammaglobulinaemia. Lancet, 2, 844 .

Janeway, C. (1954). Cases from the medical grand rounds (Massachusetts General Hospital). Case 286. Hypogammaglobulinemia in an adult. Amer. Practit., n.s. 5, 487.

Kekwick, R. A., Vallet, L., Cutbush, M., Mollison, P. L., Thomas, A. R., Gell, P. G. H. and Soothill, J. F. (1961). Estimation of gamma globulin in the serum of patients with hypogammagamma globulin in the serum of pat

Lancet (1961). Hypogammaglobulinæmia (leading article). 1, 151.

Margulis, A. R., Feinberg, S. B., Lester, R. G. and Good, R. A. (1957). Roentgen manifestations of congenital agammaglobulinemia. Radiology, 69, 354

Orlandini, O., Sass-Kortsak, A. and Ebbs, J. H. (1955). Serum gamma globulin levels in normal infants. Pediatrics, 16, 575.

Pearce, K. M. and Perinpanayagam, M. S. (1957). Congenital idiopathic hypogammaglobulinaemia. Arch. Dis. Childh., 32, 422.

Somers, K. (1957). Vaccinia gangrenosa and agammaglobulinaemia. ibid., 32, 220.

Squire, J. R. (1960). Hypogammaglobulinaemia in Great Britain. Acta haemat. (Basel), 24, 99.

Wolfson, W. Q., Cohn, C., Calvary, E. and Ichiba, F. (1948). Studies in serum proteins. Amer. J. clin. Path., 18, 723.

Wollheim, F. (1961). Inherited acquired' hypogammaglobulinaemia. Lancet, 1, 316. 